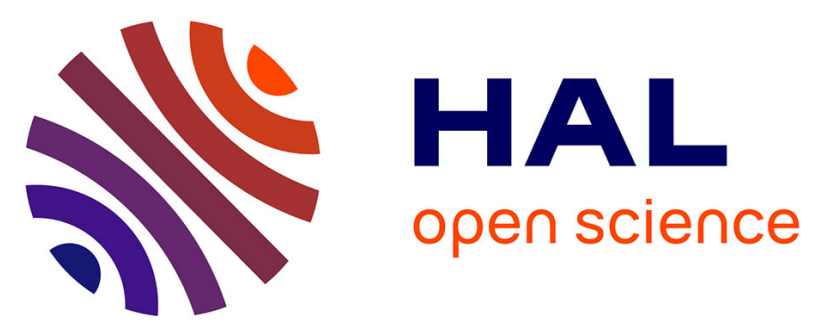

\title{
Luminescent zinc oxide nanoparticles: from stabilization to slow digestion depending on the nature of polymer coating
}

Zhiqin Zheng, Margaux Mounsamy, Nancy Lauth de Viguerie, Yannick Coppel, Simon Harrisson, Mathias Destarac, Christophe Mingotaud, Myrtil L. Kahn, Jean-Daniel Marty

\section{To cite this version:}

Zhiqin Zheng, Margaux Mounsamy, Nancy Lauth de Viguerie, Yannick Coppel, Simon Harrisson, et al.. Luminescent zinc oxide nanoparticles: from stabilization to slow digestion depending on the nature of polymer coating. Polymer Chemistry, 2019, 10 (1), pp.145-154. 10.1039/c8py01387j . hal-02129213

\section{HAL Id: hal-02129213 \\ https://hal.science/hal-02129213}

Submitted on 25 Nov 2020

HAL is a multi-disciplinary open access archive for the deposit and dissemination of scientific research documents, whether they are published or not. The documents may come from teaching and research institutions in France or abroad, or from public or private research centers.
L'archive ouverte pluridisciplinaire HAL, est destinée au dépôt et à la diffusion de documents scientifiques de niveau recherche, publiés ou non, émanant des établissements d'enseignement et de recherche français ou étrangers, des laboratoires publics ou privés. 


\title{
Luminescent Zinc Oxide Nanoparticles: From Stabilization to Slow Digestion Depending on the Nature of Polymer Coating.
}

\author{
Zhiqin Zheng, ${ }^{\mathrm{a}, \mathrm{b}, \mathrm{t}}$ Margaux Mounsamy, ${ }^{\mathrm{a}}$ Nancy Lauth-de Viguerie, ${ }^{\mathrm{a}}$ Yannick Coppel, ${ }^{\mathrm{b}}$ Simon \\ Harrisson, ${ }^{a}$ Mathias Destarac, ${ }^{a}$ Christophe Mingotaud, ${ }^{a}$ Myrtil L. Kahn*b and Jean-Daniel \\ Marty*a
}

a. Laboratoire des IMRCP CNRS UMR 5623, University of Toulouse 118, route de Narbonne 31062 Toulouse Cedex 9, France E-mail: marty@chimie.ups-tlse.fr

b. Laboratoire de Chimie de Coordination CNRS UPR 8241, University of Toulouse 205, route de Narbonne 31062 Toulouse Cedex 9, France E-mail: myrtil.kahn@lcc-toulouse.fr

t actual address: Science on Nuclear Wastes and Environmental Safety Laboratory, Sichuan Civilmilitary Integration Institute,School of life Science and Engineering, Southwest University of Science and Technology, Mianyang, China.

\begin{abstract}
Poly(ethylene glycol)-poly(vinylphosphonic acid) and poly (ethylene glycol)-poly(acrylic acid) block copolymers (PEG- $b$-PVPA and PEG-b-PAA) were synthesized by RAFT/MADIX polymerization. The interaction of PAA or PVPA block with preformed ZnO NPs and the presence of a highly soluble PEG block enable a stable colloidal solution of ZnO NPs to be obtained in both organic solvent and water. While in THF a significant enhancement of luminescent properties is observed in both cases, a slow decrease of these properties is observed in water, which is due to the slow digestion of the ZnO NPs. Lastly, compared to the PAA block, the PVPA block favors both the interaction with ZnO NPs and their digestion.
\end{abstract}

\section{Introduction}

The synthesis of luminescent inorganic nanoparticles (NPs), better known as quantum dots, with narrow size distribution and high luminescent efficiency has attracted intensive interest due to their applications in biological fluorescence labelling. ${ }^{1,2}$ Compared to traditionallyused CdSe or CdTe quantum dots, $\mathrm{ZnO}$ is an environmentally friendly and inexpensive luminescent semiconductor, which makes it very attractive for practical biological applications. ${ }^{3,4}$ Many studies have been performed to control the size and shape of the $\mathrm{ZnO}$ inorganic core and/or to choose the chemical structure of the stabilizing ligand shell. Nevertheless, the methods of functionalization generally used suffer from a lack of flexibility. The control of core size or shape is often obtained through restrictive growth conditions that require a specific combination of solvent and reducing and/or functionalizing agent.

While nanosized $\mathrm{ZnO}$ is often prepared via the sol-gel route, ${ }^{5,6}$ synthesis via an organometallic approach enables better shape control, higher crystallinity and more tunable luminescent properties but requires the use of organic solvent. ${ }^{7}$ Therefore different strategies have been developed to transfer the ZnO NPs into water. ${ }^{1,8-12}$ The first involves in situ synthesis of ZnO NPs in organic solvent in the presence of water-compatible stabilizing agents that strongly interact strongly with both the zinc precursor and the ZnO NPs. ${ }^{1,12}$ For instance, amino-terminated oligo(ethylene glycol) has been used to obtain ZnO NPs in THF that are also dispersible in water. ${ }^{12}$

Ligand exchange on the surface of preformed hydrophobic ZnO NPs is the most commonly used method to obtain water-compatible particles with controlled functionality. Understanding to what extent ligand exchange occurs and what factors affect it is important for the optimization of this critical procedure. Previously developed strategies leading to stable ZnO NPs in water have involved the use 
of molecular stabilizing agents with weak affinity to the surface of NPs, such as oleic acid or amine compounds. ${ }^{8,10,12}$ As a result, free ligands are always present in solution which is a severe drawback for biological applications. In this context, the use of polymers to promote ligand exchange and get rid more easily of remaining free ligands is of particular interest due to their multiple interactions and kinetic hindrance. Hence different families of polymers with different architectures (branched, block...) and compositions have been shown to favor ligand exchange on preformed ZnO NPs. ${ }^{9,10 b, 13 .}$ These polymers comprise a poly(ethylene glycol) (PEG) segment which is of moderate cost, approved by regulatory agencies, and water soluble at body temperature, ${ }^{14}$ as well as a hydrophobic polysiloxane ${ }^{10}$ or polymethacrylate block ${ }^{9}$ to ensure interaction with pristine hydrophobic ZnO NPs.

In this work, our main objectives are to evaluate and compare the stabilizing properties for ZnO NPs of double hydrophilic block copolymer stabilizers comprising a PEG stabilizing block and a block bearing interacting groups with high affinity for the surface of nanoparticles. The nature of the anchoring group is of paramount importance in order to promote a strong attachment of the ligand to the ZnO NPs surface. Nevertheless surface modifications can significantly impact the luminescence properties of ZnO QDs. ${ }^{10}$ Thus it is necessary to carefully control the surface chemistry in order to obtain waterstable dispersions while maintaining the emission properties. Amine and carboxy groups promote targeted luminescent properties while ensuring good anchoring to the surface of ZnO NPs. We chose here poly(acrylic acid) (PAA) as a first interacting block to promote the replacement of amine ligands present on the surface of ZnO NPs. As phosphonic acid groups also demonstrate high affinity with zinc ${ }^{15}$ and oxide based NPS like iron oxide NPs, ${ }^{16}$ a second type of diblock copolymer based on poly(vinylphosphonic acid) (PVPA) as an interacting block was also studied. ${ }^{16 a}$ We therefore describe here the synthesis of poly(ethylene glycol)-poly(acrylic acid) (PEG-b-PAA) and poly(ethylene glycol)poly(vinylphosphonic acid) (PEG-b-PVPA) double hydrophilic block copolymers of low molar mass by RAFT/MADIX polymerization. These two polymers were used to modify the surface of preformed $\mathrm{ZnO}$ NPs covered by amine ligands. The ligand exchange mechanism was studied through NMR studies, dynamic light scattering (DLS) and luminescent properties. The ability of the two block copolymers to ensure efficient colloidal stability and long-term luminescent properties of the obtained hybrid materials was studied both in THF and in water. The advantages and drawbacks of phosphonic acid groups over carboxylic acid groups are discussed, and a slow digestion mechanism is suggested in the case of ZnO NPs covered with PVPA polymer which could be of great interest for biological applications.

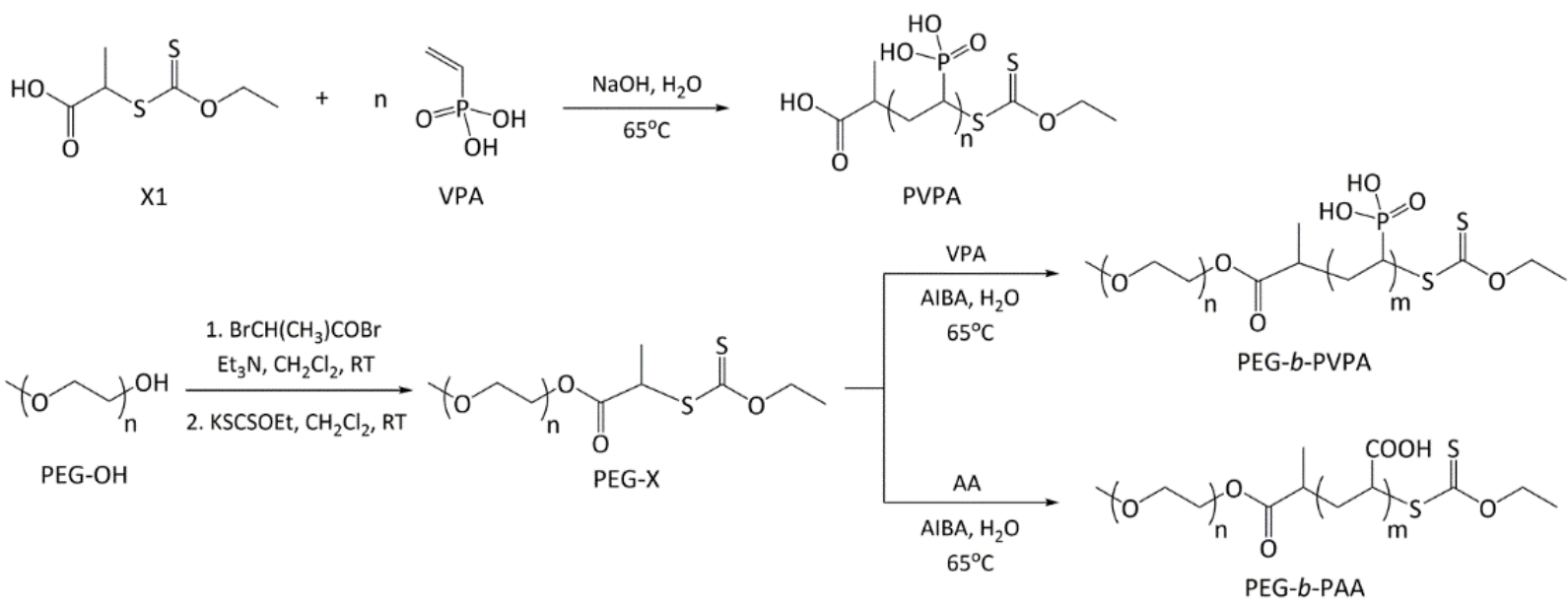

Scheme 1. Synthesis of PVPA homopolymer and diblock copolymers.

\section{Results and discussion}




\section{Synthesis of diblock copolymers}

Double hydrophilic block copolymers containing a neutral PEG segment and an ionizable segment of PVPA or PAA were synthesized by RAFT/MADIX (reversible addition-fragmentation chain transfer/macromolecular design by interchange of xanthates) polymerization from a xanthatefunctionalized PEG macroRAFT agent (Scheme 1 ) as previously described. ${ }^{16}$ The PEG macroRAFT agent with a number-average molecular weight $\left(M_{n}\right)$ of $2000 \mathrm{~g} . \mathrm{mol}^{-1}$ was prepared in a two-step synthesis from $\omega$-hydroxy-functional PEG. ${ }^{17}$ Chain extension was then carried out by polymerizing AA or VPA in water, targeting $M_{n}$ of $1000 \mathrm{~g} \cdot \mathrm{mol}^{-1}$. This corresponds to a number-average degree of polymerization $\left(D P_{n}\right)$ of 13 and 9 respectively. Conditions for the VPA polymerization were adapted from those reported by Layrac et al. ${ }^{18 a}$ for the synthesis of polyacrylamide- $b$-PVPA. In all cases, the polymerizations reached approximately $50 \%$ conversion after $8 \mathrm{~h}$ of reaction at $65^{\circ} \mathrm{C}$; unreacted VPA monomer was then removed by dialysis $\left(\mathrm{MWCO}=1000 \mathrm{~g} \cdot \mathrm{mol}^{-1}\right) \cdot{ }^{18 \mathrm{~b}}$

Table 1. Summary of molecular weights of homopolymers and diblock copolymers used for the stabilization of ZnO NPs based on SEC and ${ }^{1} \mathrm{H}$ NMR.

\begin{tabular}{|c|c|c|c|c|}
\hline & $\begin{array}{l}M_{n, t^{a}} \\
\left(g \cdot \mathrm{mol}^{-1}\right)\end{array}$ & $\begin{array}{l}\mathrm{Mn} \mathrm{NMR}^{\mathrm{b}} \\
\left(\mathrm{g} \cdot \mathrm{mol}^{-1} \text { ) }\right.\end{array}$ & 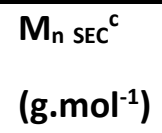 & $\boldsymbol{D}$ \\
\hline $\mathrm{PEG}_{2 \mathrm{k}}$ & 2188 & nd & 2000 & 1.09 \\
\hline $\mathrm{PAA}_{1 \mathrm{k}}$ & 1000 & 1050 & 1000 & 1.18 \\
\hline $\mathrm{PVPA}_{1 \mathrm{k}}$ & 944 & 960 & 2900 & 1.20 \\
\hline $\mathrm{PEG}_{2 \mathrm{k}}-b-\mathrm{PAA}_{1 \mathrm{k}}$ & 2998 & 3130 & 2900 & 1.03 \\
\hline $\mathrm{PEG}_{2 \mathrm{k}}-b-\mathrm{PVPA}_{1 \mathrm{k}}$ & 3820 & 3530 & 3500 & 1.17 \\
\hline
\end{tabular}

${ }^{a} M_{n, t h}=\left([m o n o m e r]_{0} /[X]_{0}\right)^{*} C_{\text {Conv }} * M($ monomer $)+M(X) . \quad M_{V P A}=108$ g.mol ${ }^{-1}, M_{A A}=72 \quad$ g.mol ${ }^{-1}, M_{P E G 2 k-}$ $\mathrm{x}=2188 \mathrm{~g}$. $\mathrm{mol}^{-1} .{ }^{\mathrm{b}}$ Determined by ${ }^{1} \mathrm{H}$ NMR taking the molar mass of the PEG block into account. ${ }^{\mathrm{c}}$ Measured by SEC-RI-MALS. ${ }^{d} \mathrm{PEG}_{2 \mathrm{k}}$ is a commercially available product (PEG-OH).

The block copolymers were characterized by NMR $\left({ }^{1} \mathrm{H}\right.$ and $\left.{ }^{31} \mathrm{P}\right)$ and size exclusion chromatography (SEC). Molecular weight distributions were narrow $(\theta<1.2)$, and good agreement was observed between the theoretical $M_{n}\left(M_{n, t h}\right)$ and the apparent $M_{n}$ obtained from either NMR or SEC (Table 1). In addition, a shift to lower elution volumes was observed in the SEC trace of the block copolymer relative to the PEG substrate, indicating complete transformation of the macroRAFT agent into block copolymer (Figure S1 in Supporting Information).

An analogous $\mathrm{PEG}_{2 \mathrm{k}}-b-\mathrm{PAA}_{1 \mathrm{k}}$ copolymer was prepared by substituting AA for VPA in the method above. As for the PEG- $b$-PVPA copolymers, SEC analysis revealed narrowly distributed polymer with good agreement between theoretical and observed molecular weights and a clear shift to lower elution volume relative to the macroRAFT agent. All block copolymers prepared in this work are listed in Table 1. Additionally, homopolymers of PAA and PVPA were prepared by RAFT from the carboxy-xanthate RAFT agent X1 (Scheme 1) for comparison with the block copolymers. The differences in $M_{n}$ values 
determined by NMR and SEC-MALS for PVPA 1 K are well understood and have been explained in a recent publication. ${ }^{18 b}$ Their characteristics are also shown in Table 1

\section{Synthesis of Zinc Oxide Nanoparticles and stabilization in THF.}

Formation of $\mathrm{ZnO}$ nanoparticles was performed via a one-step hydrolysis of dicyclohexyl zinc $\left(\left[\mathrm{Zn}(\mathrm{Cy})_{2}\right]\right)$ precursor in THF in the presence of $n$-octylamine (OA) (Scheme 2).

An equimolar ratio of $\mathrm{OA}$ to $\left[\mathrm{Zn}(\mathrm{Cy})_{2}\right]$ was used. The solution containing $\left[\mathrm{Zn}(\mathrm{Cy})_{2}\right]$ and $\mathrm{OA}$ was prepared in a glove box under argon, then a defined quantity of water was added leading after hydrolysis to the formation of $\mathrm{ZnO}$ isotropic NPs. This method involves the use of long alkyl chain amine ligands as stabilizers and takes advantage of the exothermic hydrolysis of organometallic complexes in air. Using $\left[\mathrm{Zn}(\mathrm{Cy})_{2}\right]$ as a precursor provides a safer synthetic method than other organometallic complexes such as diethyl zinc, used by Richter and co-workers as its hydrolysis is more easily controllable. ${ }^{19,20}$ Control over the kinetics of $\mathrm{ZnO}$ formation was ensured by the interactions occurring between amine ligands and $\left[\mathrm{Zn}(\mathrm{Cy})_{2}\right]$ or $\mathrm{ZnO} \mathrm{NPs}$, which have been reported to affect the size and shape of the synthesized $\mathrm{ZnO} \mathrm{NPs}{ }^{21 a}$ as well as their optical properties. ${ }^{21 b}$ In order to ensure a good control over the ZnO NPs size and morphology, we opted for a ligand exchange process between block copolymer and OAprotected ZnO NPs (Scheme 2) instead of the direct synthesis of the NPs in the presence of the block copolymer.

Block copolymers $\mathrm{PEG}_{2 \mathrm{k}}-b-\mathrm{PVPA}_{1 \mathrm{k}}$ and $\mathrm{PEG}_{2 \mathrm{k}}-b-\mathrm{PAA}_{1 \mathrm{k}}$ were added to the preformed $\mathrm{ZnO}$ NPs in THF (Figure S2 in Supporting Information). An equimolar ratio of acidic function of copolymer to zinc precursor was used. For these polymers, the presence of several acid functions (either acrylic acid or phosphonic acid groups) should guarantee interactions with ZnO NPs. Moreover, the PEG chains not only act as an external polar layer providing good solubility in organic solvents and in water, but also improve the biocompatibility of the hybrid.

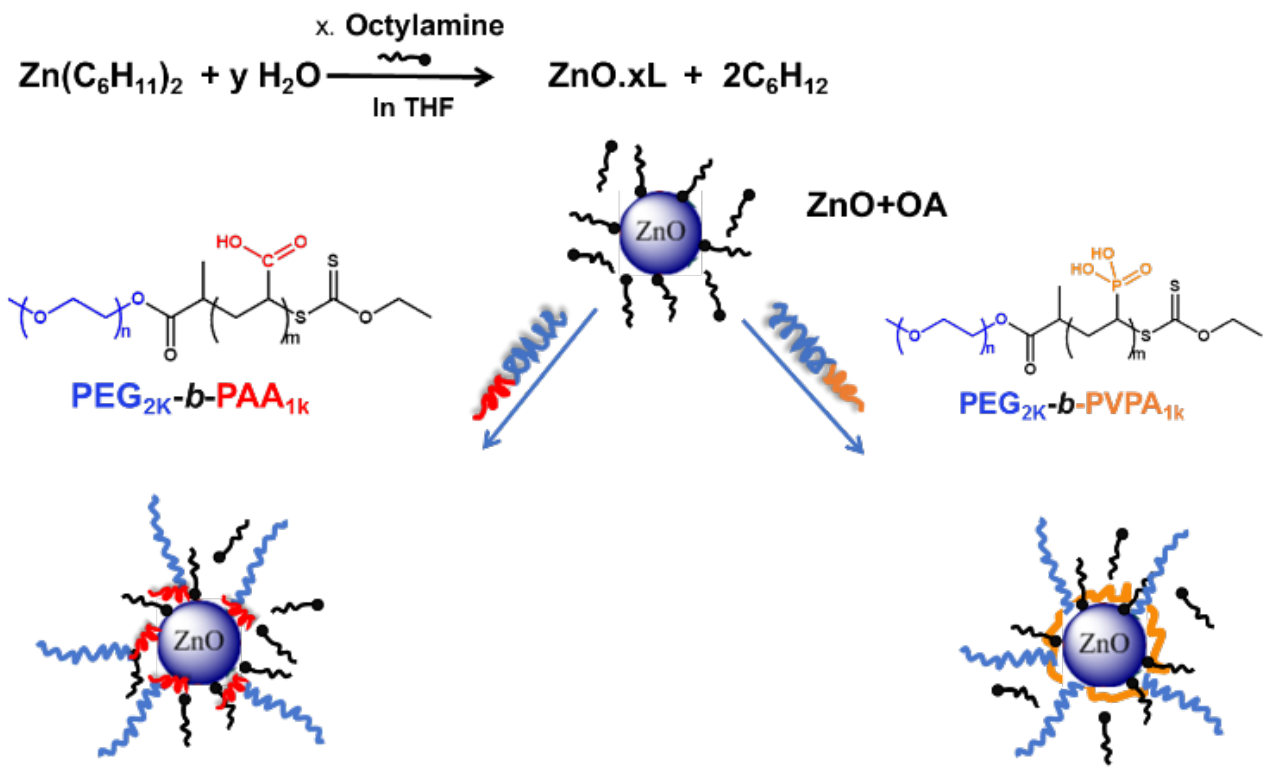

Scheme 2. Isotropic $\mathrm{ZnO}$ NPs synthesized by n-octylamine $(O A)$ and the schematic representation (deduced from NMR results as depicted below) for the coated process by two polymers respectively. 
The polymer-modified ZnO NPs were first analyzed by TEM. The diameter of the NPs were $6 \pm 4 \mathrm{~nm}$ and $5 \pm 3 \mathrm{~nm}$ respectively for $\mathrm{PEG}_{2 \mathrm{k}}-b-\mathrm{PAA}_{1 \mathrm{k}}$ (Figure $1 \mathrm{~A}$ ) and $\mathrm{PEG}_{2 \mathrm{k}}-b-\mathrm{PVPA}_{1 \mathrm{k}} 48 \mathrm{~h}$ after modifications (see Figure $\mathrm{S} 3 \mathrm{C}$ in supporting information). Therefore, as expected, no significant change in NP size was observed compared to the ZnO NPs before modification. As depicted in Figure 1B, a 2D-plot of the different samples is characteristic of isotropic NPs (point cloud centered on the diagonal). ${ }^{22}$

A
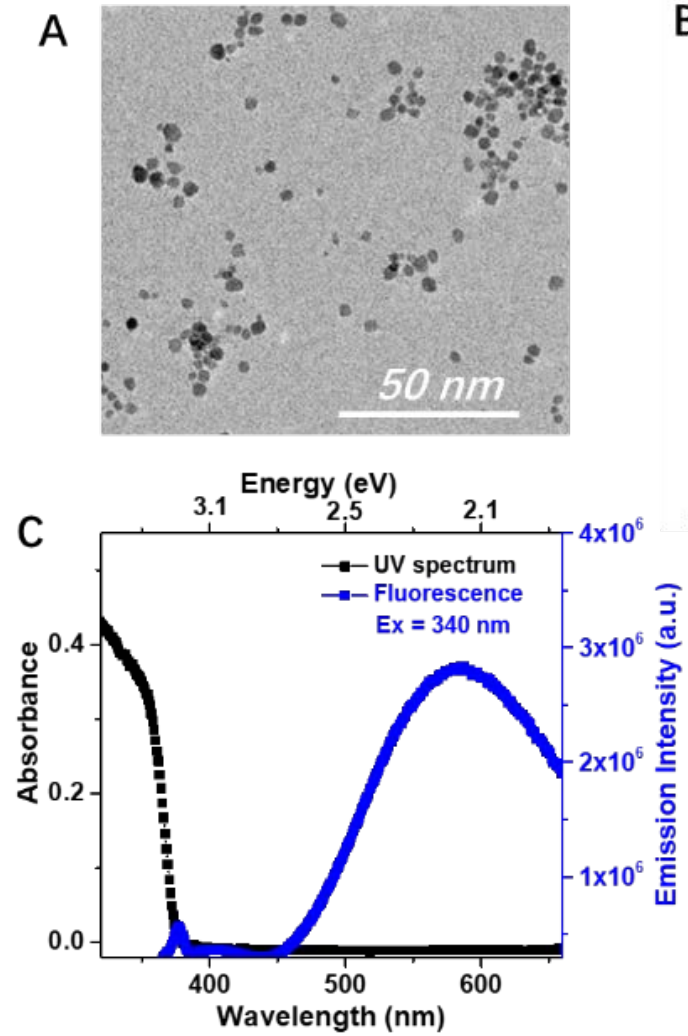

B

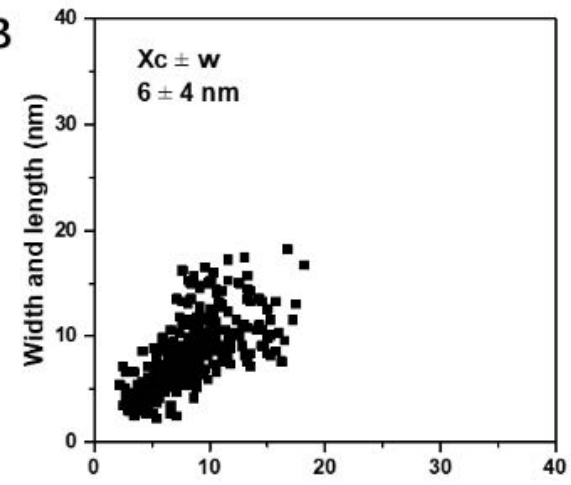

Width and length (nm)

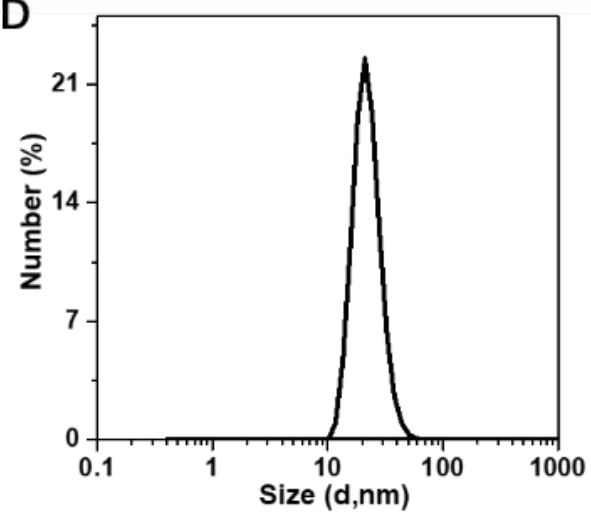

Figure 1. Analysis of $(\mathrm{ZnO}+\mathrm{OA})+\mathrm{PEG}_{2 \mathrm{~K}}-b-P A A_{1 k}$ in THF. A: TEM image of $\mathrm{ZnO} N P s$. B: 2D plot of diameter of ZnO NPs.C: Spectrum for the absorption (black squares) and yellow emission (blue square) ( $\lambda_{\text {exc }}=$ $340 \mathrm{~nm}$ ). D: Number-averaged size distribution of hydrodynamic diameter obtained from DLS measurement.

In solution, the intensity-averaged and number-averaged hydrodynamic diameters of these modified $\mathrm{ZnO}$ NPs was $20 \pm 5 \mathrm{~nm}$ for both polymers (Figure S4 in supporting information). Pristine NPs present a number-averaged hydrodynamic diameter of around $200 \mathrm{~nm}$ meaning that they are mostly present as aggregates of NPs in THF solutions. Therefore, modification of the surface of NPs by adsorption of the polymer enables isolated (or nearly isolated) ZnO NPs to be obtained in solution. This behavior is corroborated by TEM images showing more dispersed NPs in the case of polymer-modified NPs (see Figure $\mathrm{S} 3$ in supporting information).

$\mathrm{ZnO}$ possesses intriguing luminescent properties in the visible range. We studied the photoluminescent properties of ZnO NPs modified by the two polymers. Both solutions were luminescent under a UV lamp (at $365 \mathrm{~nm}$ ) after redispersion in THF (Figure S5 in supporting information). All samples display similar absorption spectra, typically a strong absorption is observed up to around $355 \mathrm{~nm}(\approx 3.49 \mathrm{eV})$ followed by a sharp decrease (Figure $\mathrm{S} 6$ in supporting information). This is characteristic of nanometric 
zinc oxide with a band-gap at approximately $365 \mathrm{~nm}(\approx 3.4 \mathrm{eV})$. The absorption and emission spectra of polymer-stabilized ZnO NPs are displayed in Figure $1 \mathrm{C}$ and Figure S7 in supporting information. A broad emission band in the visible region was observed for all samples. This yellow emission was centered at $575 \mathrm{~nm}$ for an excitation wavelength between 300 and $360 \mathrm{~nm}(\approx 4.13$ to $3.44 \mathrm{eV})$ and originates from $\mathrm{ZnO}$ surface defects such as oxygen vacancies. ${ }^{23}$

We then studied the evolution of these photoluminescence properties over a one week period as depicted in Figure 2 and in Figure S5-S7 in supplementary information. The evolution of luminescence depends strongly on whether polymers are present: luminescence remains constant for pristine $\mathrm{ZnO}$ NPs (without polymer), but a strong increase of luminescence (of around $100 \%$ ) is observed for $\mathrm{ZnO}$ NPs modified by the polymers. These modifications may be induced by changes in the ZnO surface induced by polymer adsorption and displacement of OA. No significant change in absorbance was observed for any of the solutions tested, indicating that stable colloidal solutions were obtained in all cases. This is confirmed by TEM and DLS analyses that show no measurable change after one week.

NMR experiments were performed to obtain further insights on the changes occurring when the polymer is added to ZnO NPs. In THF- $d_{8}$ (Figure S8 in supporting information), the ${ }^{1} \mathrm{H}$ NMR lineshapes are sharp, no transfer NOE (tr-NOE) signals are detected for $\mathrm{OA} \mathrm{H}$ atoms and only one diffusion coefficient is observed with a value of $2.110^{-9} \mathrm{~m}^{2} . \mathrm{s}^{-1}$ by DOSY NMR, contrary to what has been observed in toluene- $d_{8}{ }^{24}$ where at least three different modes of interaction of the amines at the surface of the NPs have been observed in thermodynamic equilibrium with the free amines. Thus, in THF, the equilibrium seems to be displaced toward a high population of free amine molecules probably because of competition with THF molecules that can also bind to the $\mathrm{ZnO}$ surface.

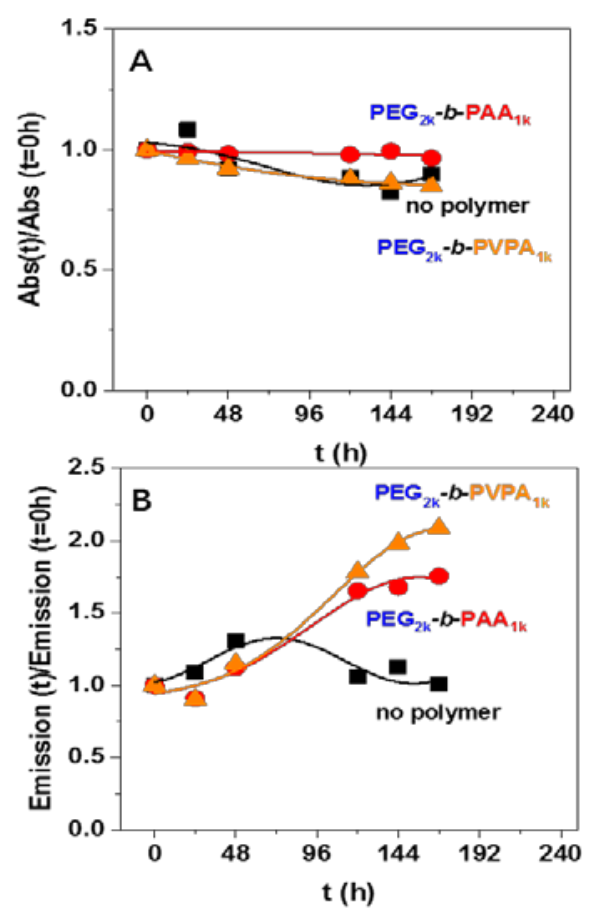

Figure 2. Evolution through time of $A$ : normalized absorbance and $B$ : normalized emission $(\lambda \operatorname{exc}=340$ $\mathrm{nm}$ ) of THF dispersions of ZnO NPs coated by octyl amine or by OA/PEG $2 \mathrm{k}-b-\mathrm{PAA}_{1 \mathrm{k}}$ or OA/PEG $\mathrm{Pk}_{\mathrm{k}}-b$ $\mathrm{PVPA}_{1 \mathrm{k}} \mathrm{B}$. Corresponding luminescence of these solutions (samples are irradiated at $365 \mathrm{~nm}$ ). Normalized absorbance and emission were obtained from Figure S6 and S7, see SI for details). 
In THF- $d_{8}$ and in the presence of $\mathrm{PEG}_{2 \mathrm{k}}-b$-PAA $\mathrm{A}_{1 \mathrm{k}}$ polymer, the OA signals become broader, especially that of $\mathrm{CH}_{2}\left(\mathrm{NH}_{2}\right)$ at $2.6 \mathrm{ppm}$ (Figure $\mathrm{S} 9$ in supporting information). For the $\mathrm{PEG}_{2 \mathrm{k}}-b-\mathrm{PAA} \mathrm{A}_{1 \mathrm{k}}$ polymer, only the signals of PEG functions between 3.3 and $3.7 \mathrm{ppm}$ are clearly observed, suggesting interaction between the polymer and the nanoparticles surface through AA functions. A decrease in the average diffusion coefficient associated with the PEG moieties is observed in the presence of the nanoparticles (from 3.5 to $0.210^{-10} \mathrm{~m}^{2} \cdot \mathrm{s}^{-1}$ ). OA shows a slight decrease of its diffusion coefficient (from 2.1 to $1.510^{-}$ ${ }^{9} \mathrm{~m}^{2} \cdot \mathrm{s}^{-1}$ ). Strong tr-NOE signals are observed between intramolecular $\mathrm{H}$ atoms of $\mathrm{OA}$ and also between $\mathrm{H}$ atoms of $\mathrm{OA}$ and $\mathrm{PEG} .{ }^{25}$ These results indicate a weak interaction between $O A$ and the $P E G_{2 k}-b-P A A_{1 k}$. This interaction explains the notable broadening of the $O A{ }^{1} \mathrm{H}$ resonances, probably due to rapid exchange between free neutral OA molecules and protonated OA molecules interacting with the $\mathrm{PEG}_{2 \mathrm{k}^{-}}$ $b$-PAA $A_{1 k}$ polymer through acid-base reaction. Similar results for $O A$ and $P^{2} G_{2 k}-b-P A A_{1 k}$ are observed when they are mixed in the absence of the ZnO NPs: i) diffusion coefficients decrease for the PEG moieties (from 3.5 to $0.410^{-10} \mathrm{~m}^{2} . \mathrm{s}^{-1}$ ) and for the OA molecules (from 2.1 to $1.510^{-9} \mathrm{~m}^{2} . \mathrm{s}^{-1}$ ) and ii) trNOE signals are observed between intramolecular OA $H$ atoms and between OA and PEG $\mathrm{H}$ atoms. However, the decrease of the PEG diffusion coefficient and the tr-NOE signal intensities are significantly weaker in the absence of NPs giving evidence for an interaction between the $P G_{2 k}-b$ $\mathrm{PAA}_{1 \mathrm{k}}$ polymer and the ZnO NPs. OA molecules probably play mostly a role of mobile counter ion (ammonium form) of carboxylate groups in the polymer, in fast exchange with a much higher population of free neutral OA molecules. These results are in agreement with previous observations of $\mathrm{ZnO} / \mathrm{OA}$ nanoparticles in the presence of long chain alkyl carboxylic acid ligands. ${ }^{26}$

Solid state NMR spectra performed on $\mathrm{ZnO} / \mathrm{OA} / \mathrm{PEG}_{2 \mathrm{k}}-b-\mathrm{PAA}_{1 \mathrm{k}}$ gel sample gives additional evidence of direct interactions between the polymer and the surface of the nanoparticle (Figures $3 \mathrm{~A}$ and Figure S10 in supporting information): i) broad signals associated with the PAA functions are observed in the ${ }^{13}$ C CPMAS experiment in the presence of ZnO NPs while no signals are detected in the absence of NPs; ii) the reverse is observed in the ${ }^{13} \mathrm{C}$ CPMAS experiment where sharp PAA signals are detected only in the absence of nanoparticles. These results indicate a strong rigidification of the PAA groups in presence of the ZnO NPs that lead to: i) a broadening of PAA resonances due to structural heterogeneity; ii) an increase of ${ }^{1} \mathrm{H}-{ }^{13} \mathrm{C}$ dipolar coupling strength resulting in the appearance of the ${ }^{13} \mathrm{C}$ CPMAS signals and iii) an increase of the ${ }^{13} \mathrm{C}$ relaxation times resulting in a strong decrease in the signal intensity of the ${ }^{13} \mathrm{C}$ MAS spectrum. These results are certainly due to the interaction of the PAA moieties through the carboxylic functions with the nanoparticle surface. 

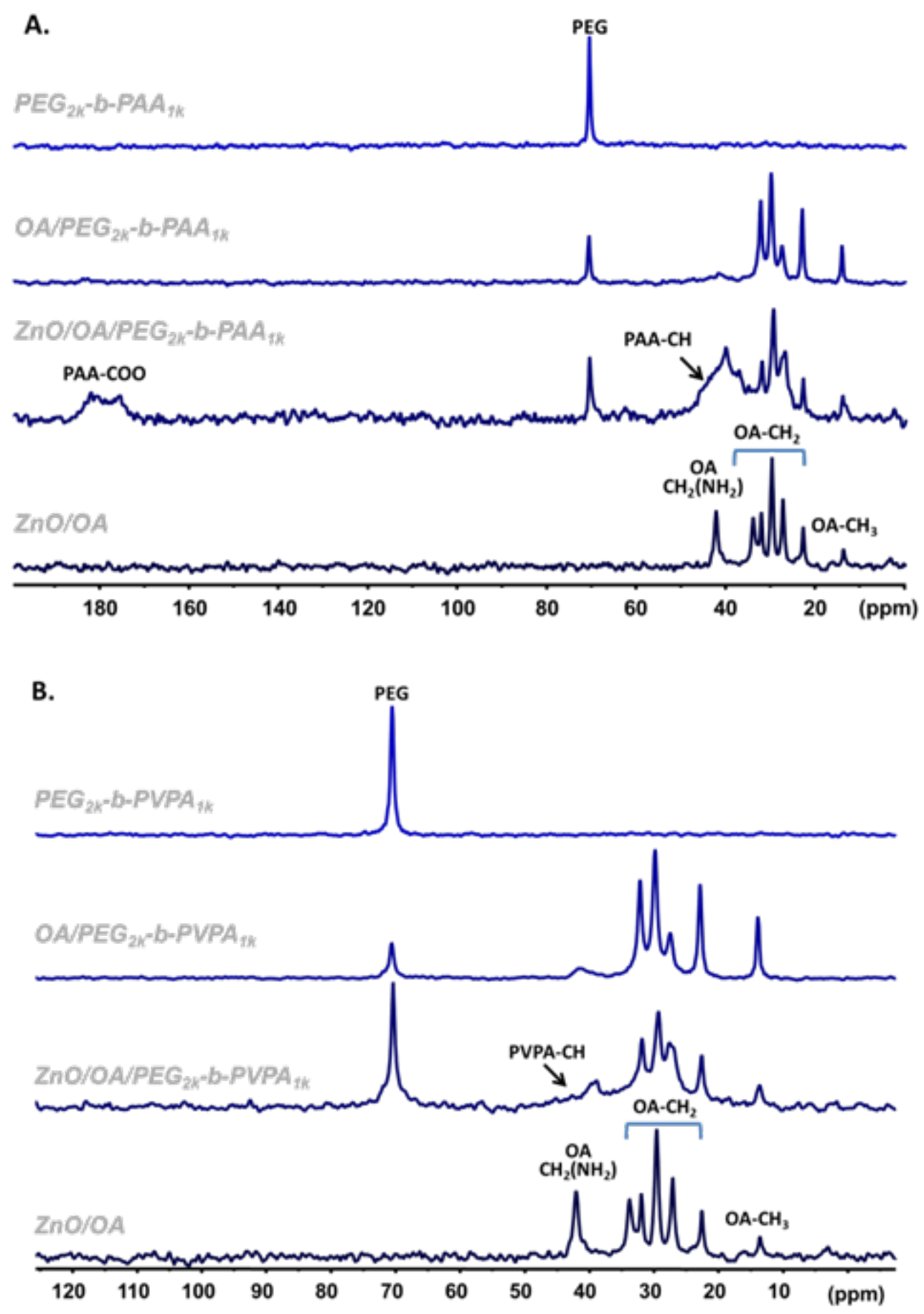

Figure 3. ${ }^{13} \mathrm{C} C P M A S$ NMR spectra of $A: Z n O / O A / P E G_{2 k}-b-P A A_{1 k}$ and $B: Z n O / O A / P E G_{2 k}-b-P V P A_{1 k}$ system. Spectra obtained for these systems were compared with the one issued from $\mathrm{ZnO} / \mathrm{OA}$, the polymers alone and from a mixture of $\mathrm{OA} /$ polymer.

When $P E G_{2 k}-b-P V P A_{1 k}$ is used instead of $P E G_{2 k}-b-P A A_{1 k}$, the interaction between PVPA moieties and OA is slightly different. DOSY and NOESY experiments showed that the population of OA that interacts weakly with the PVPA polymer is smaller than in the case of the PAA polymer (Figure S11 in supporting information). However, diffusion filtered ${ }^{1} \mathrm{H} N \mathrm{NMR}$ (Figure $\mathrm{S} 12$ in supporting information) indicated that a small portion of OA interacts strongly with the $P E_{2 k}-b-P V P A_{1 k}$ polymer while for the $P E G_{2 k}-b-P A A_{1 k}$ polymer a weaker interaction is observed. Broad PVPA signals are detected in the presence of ZnO NPs 
(Figure 3B and S13A in supporting information). ${ }^{31} \mathrm{P}$ CPMAS experiments showed that the $\mathrm{POO}(\mathrm{H})$ of PVPA becomes more rigid in the presence of OA molecules (Figure S13B in supporting information). However ${ }^{13} \mathrm{C}$ (CP)MAS NMR experiments were less clear due to the remoteness of carbon atoms from the $\mathrm{ZnO}$ surface. The OA/PEG $2 \mathrm{k}-b-\mathrm{PVPA}_{1 \mathrm{k}}$ and $\mathrm{ZnO} / \mathrm{OA} / \mathrm{PEG}_{2 \mathrm{k}}-b-\mathrm{PVPA}_{1 \mathrm{k}}$ samples show ${ }^{31} \mathrm{P}$ chemical shift anisotropy that is averaged to zero in the $\mathrm{PEG}_{2 \mathrm{k}}-b-\mathrm{PVPA}_{1 \mathrm{k}}$ polymer alone by local motions. The ${ }^{31} \mathrm{P} N \mathrm{NM}$ resonances showed a shift of $6.6 \mathrm{ppm}$ between the OA/ $\mathrm{PEG}_{2 \mathrm{k}}-b-\mathrm{PVPA}_{1 \mathrm{k}}$ and $\mathrm{ZnO} / \mathrm{OA} / \mathrm{PEG}_{2 \mathrm{k}}-b-\mathrm{PVPA}_{1 \mathrm{k}}$ sample due to the interaction of PVPA with the $\mathrm{ZnO}$ surface.

All the data collected by NMR, DLS and TEM experiments demonstrate that, in THF, the block copolymers were adsorbed on the surface of ZnO NPs. Additionally, $\mathrm{PEG}_{2 \mathrm{k}}-b-\mathrm{PAA}_{1 \mathrm{k}}$ and $\mathrm{PEG}_{2 \mathrm{k}}-b-\mathrm{PVPA}_{1 \mathrm{k}}$ interact with OA through acid-base reaction.

\section{Transfer of ZnO NPs in water}

In order to transfer ZnO NPs from THF to water, THF was first evaporated. The resulting powder was dispersed in water and sonicated. The $\mathrm{pH}$ of the obtained colloidal solutions was found between 6.8 and 7.2. The presence of the copolymers enabled the transfer of ZnO NPs from THF to water (Figures $4 \mathrm{~B}$ and $4 \mathrm{C}$ ) whereas $\mathrm{ZnO}$ NPs covered by OA alone could not be redispersed in water (Figure 4A). In the presence of polymers, the transfer was visualized by yellow luminescence of $\mathrm{ZnO}$ and the number of NPs solubilized in the aqueous phase was evaluated from measurements of the absorbance. The absorbance spectra display clear evidence of the presence of $\mathrm{ZnO} /$ copolymer nanohybrids dispersed in the water solution. TEM observations of the ZnO NPs before and after transfer showed that the morphology of the ZnO NPs (diameter $6 \pm 3 \mathrm{~nm}$, Figure S14 in supporting information) is not significantly modified. DLS (Figure S15 in supporting information) was used to determine a number average hydrodynamic diameter of around $20 \mathrm{~nm}$. This value is comparable to that obtained in THF before transfer. Hence a successful transfer of modified ZnO NPs as single NPs from THF to water was obtained.

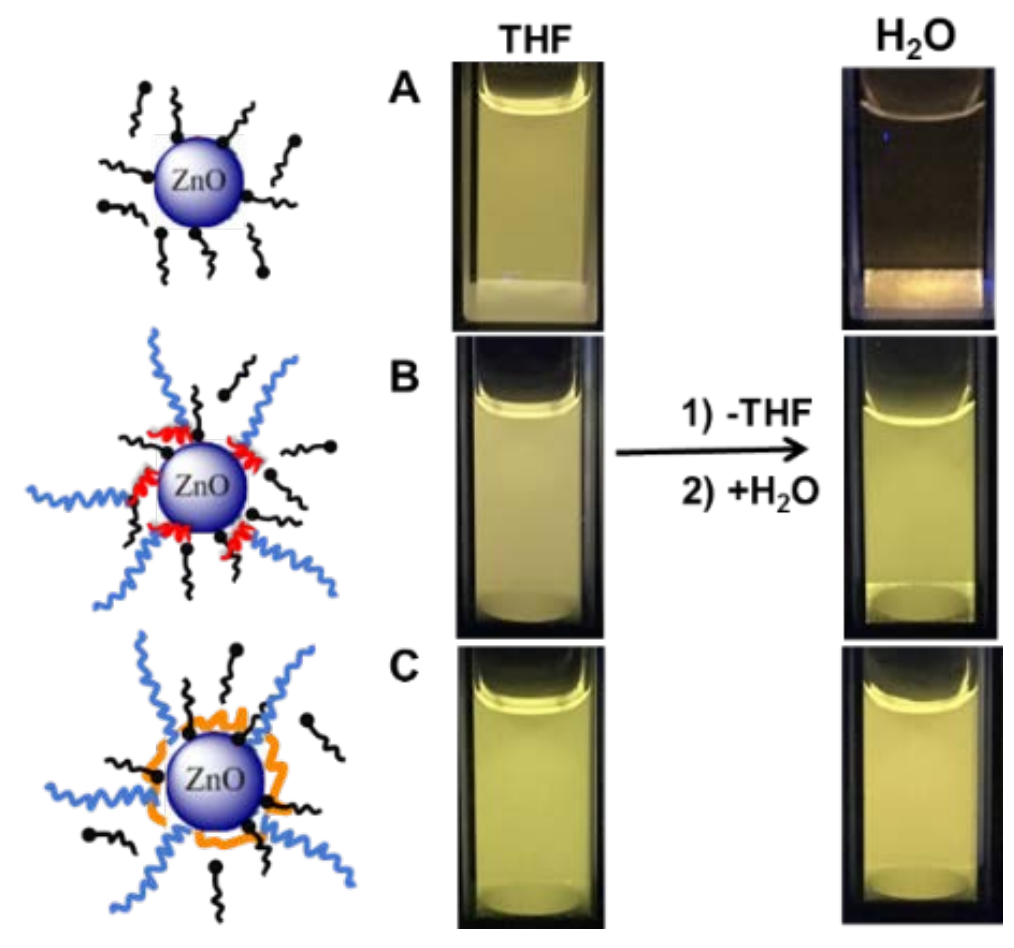

Figure 4. Luminescence of solution of $\mathrm{ZnO} N P s$ formed in the presence of octyl amine (A) and coated by $\mathrm{PEG}_{2 \mathrm{k}}-b-\mathrm{PAA}_{1 \mathrm{k}}(\mathrm{B})$ and $\mathrm{PEG}_{2 \mathrm{k}}-b-\mathrm{PVPA}_{1 \mathrm{k}}(\mathrm{C})$ in THF and after transfer in water (samples are irradiated at $365 \mathrm{~nm}, 24 \mathrm{~h}$ after the transfer) 
To further investigate the effect of polymer structure on the stabilization of ZnO NPs we added a concentrated $\mathrm{NaCl}$ solution to reach a final concentration of $5 \mathrm{mmol}^{-1}$ (Figure 5). Under these conditions initial OA-covered ZnO NPs aggregate quickly and then totally precipitate in one day. The same phenomenon is observed in the presence of the homopolymers $P A A_{1 k}$ and $P E G_{2 k}$. In all these cases, electrostatic repulsions should be responsible (at least in part) for the colloidal stability. Only the use of copolymer $\mathrm{PEG}_{2 \mathrm{k}}-\mathrm{b}-\mathrm{PAA}_{1 \mathrm{k}}$ produced solution that were stable for 10 days, even in the presence of salt. The same behavior was observed for $P E_{2 k}-b-P V P A_{1 k}$. This clearly demonstrates that the block structure of the polymer with a PEG block is necessary to obtain nanohybrids with enhanced colloidal stability in water.

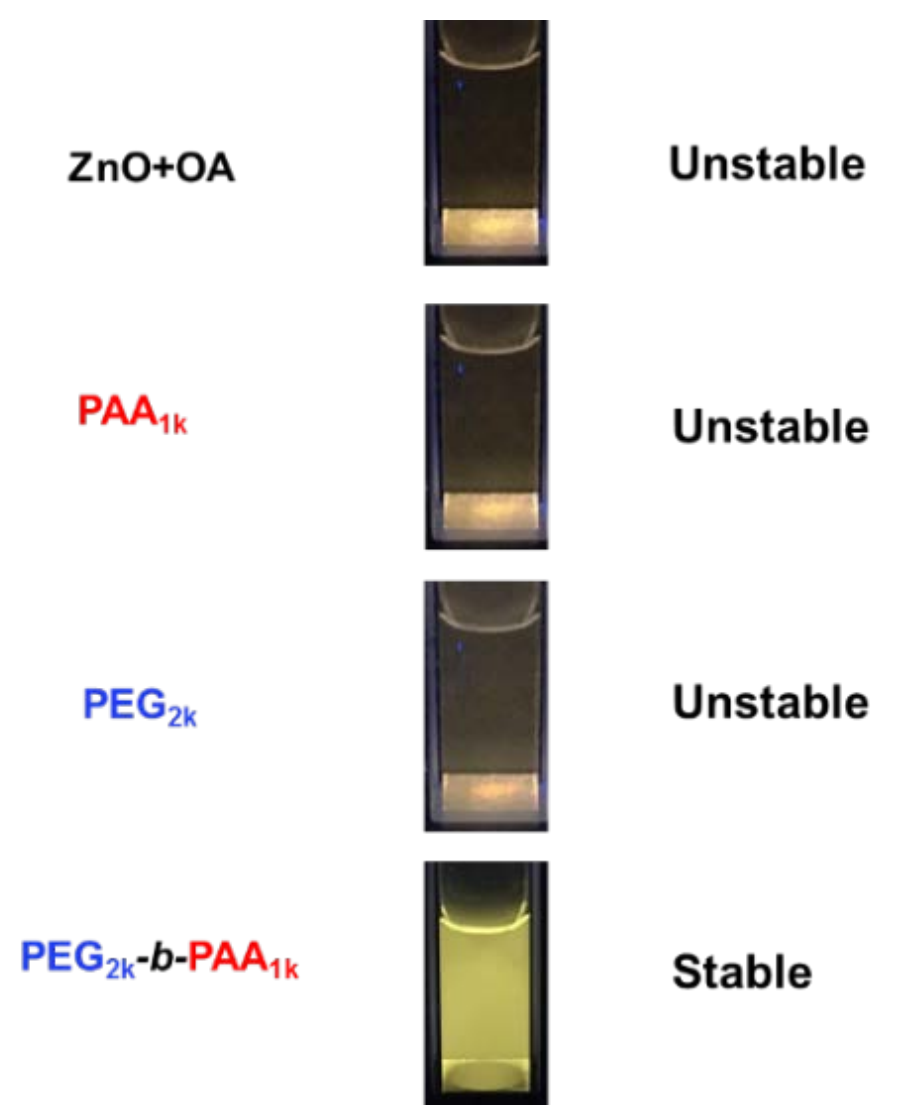

Figure 5. Luminescence of aqueous solution of $\mathrm{ZnO} N P s$ formed in the presence of $\mathrm{OA}(\mathrm{ZnO}+\mathrm{OA})$ coated by $\mathrm{PAA}_{1 \mathrm{k}}, \mathrm{PEG}_{2 \mathrm{k}}$ and $\mathrm{PEG}_{2 \mathrm{k}}-b-\mathrm{PAA}_{1 \mathrm{k}}$ after addition of $\mathrm{NaCl}$ (final concentration=5 $\mathrm{mmol} \cdot \mathrm{L}^{-1}$ ). Samples are irradiated at $365 \mathrm{~nm}$. Photos were taken one day after transfer in water

The luminescence of the NP/copolymer systems in water was then studied over several days. For both copolymers, a decrease of the absorbance (Figure 6A) and of the luminescence (Figure 6B and Figure S16 in supporting information) were observed through time. This could be related to two phenomena: i) a partial precipitation or ii) a structural modification or digestion of $\mathrm{ZnO}$ particles over time. 

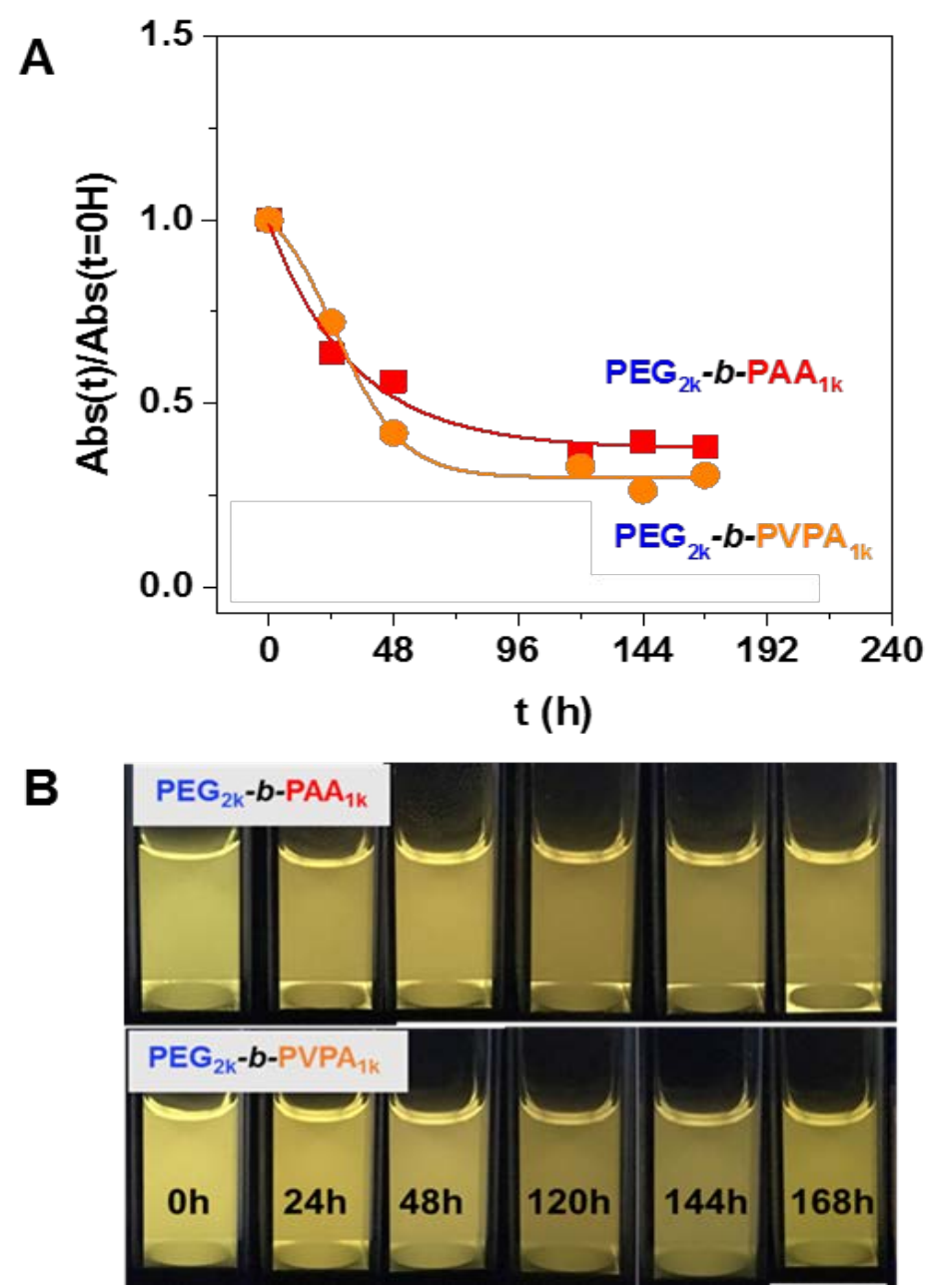

Figure 6. A. Evolution through time of normalized absorbance at $350 \mathrm{~nm}$ of $\mathrm{ZnO}$ NPs coated by octyl amine or by $\mathrm{OA} / \mathrm{PEG}_{2 \mathrm{k}}-\mathrm{b}-\mathrm{PAA}_{1 \mathrm{k}}$ or $\mathrm{OA} / \mathrm{PEG}_{2 \mathrm{k}}-\mathrm{b}-\mathrm{PVPA}_{1 \mathrm{k}}$ after transfer in water after $0,24,48,120,144$ and 168 hours (normalized absorbance was obtained from Figure S16, see SI for details). B. Corresponding luminescence of these solutions (samples are irradiated at $365 \mathrm{~nm}$ )

When the NMR study is performed in $\mathrm{D}_{2} \mathrm{O}$ for $\mathrm{ZnO} / \mathrm{OA}$, the signals of strongly bound ligand at the $\mathrm{ZnO}$ surface are observed (with a diffusion filter experiment as depicted in Figure S17 in supporting information) but disappears quickly with time. Moreover a release of OA and THF molecules in the solution is observed that induces the precipitation of the nanoparticles over time. Such results should be related to hydroxylation of the nanoparticle surface. ${ }^{27}$ Interestingly, in the presence of $\mathrm{PEG}_{2 \mathrm{k}}$-b$\mathrm{PAA}_{1 \mathrm{k}}$, the release of OA and THF is significantly slower (Figure S18 in supporting information). The hydroxylation of the surface is delayed. Interaction of OA with PAA may account for this result. The system is slightly less stable in the presence of $\mathrm{PEG}_{2 \mathrm{k}}-b$-PVPA $\mathrm{P}_{1 \mathrm{k}}$ (Figure $\mathrm{S} 19$ in supporting information) as shown by $1 \mathrm{D}$ diffusion filter experiments that showed a faster loss of the population of slow diffusing species (OA and polymer in interaction with NPs) over time in presence of $\mathrm{PEG}_{2 \mathrm{k}}-b-\mathrm{PVPA}_{1 \mathrm{k}}$ than in presence of $\mathrm{PEG}_{2 \mathrm{k}}-b-\mathrm{PAA}_{1 \mathrm{k}}$. During this time, only release from the NP surface of THF molecules and of a small quantity of OA molecules is observed by $1 \mathrm{D}{ }^{1} \mathrm{H}$ NMR, ruling out OA and PVPA precipitation. These results suggest a digestion of $Z \mathrm{nO} N P s$ over time with $\mathrm{PEG}_{2 \mathrm{k}}-b-\mathrm{PVPA}_{1 \mathrm{k}}$. 
To summarize, in water, the interaction between $P E_{2 k}-b-P A A_{1 k}$ or $P E_{2 k}-b-P V P A_{1 k}$ and $O A$ is favorable since the presence of the polymer prevents fast hydroxylation of the surface. The release of OA from the surface is significantly slower than for $\mathrm{ZnO} / \mathrm{OA}$ and the precipitation of the nanoparticles is delayed. However, in the case of PVPA digestion of the nanoparticles over time is suggested.

\section{Stability of $\mathrm{ZnO}$ nanorods}

Further experiments were performed with $\mathrm{ZnO}$ nanorods, whose shape will enable us to have further insight on this digestion process. ZnO nanorods were obtained by hydrolysis of the zinc precursor in presence of 1 molar equivalent of OA without additional solvent at room temperature over 12 hours. Figure 7 depicts a TEM image of the obtained nanorods. Their dimensions are $36 \pm 14 \mathrm{~nm}$ by $6 \pm 1 \mathrm{~nm}$.
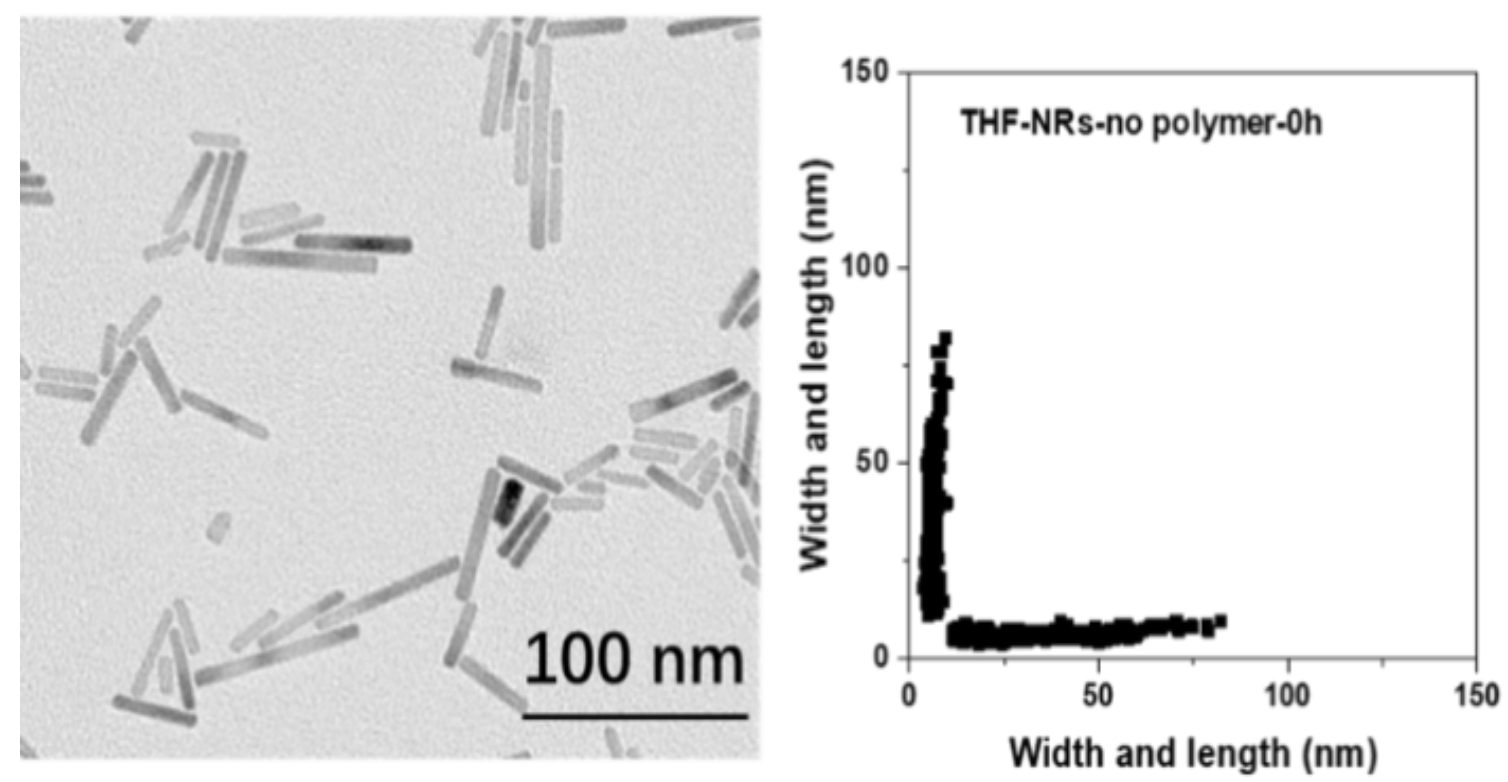

Figure 7. TEM images and corresponding 2D-plot of $\mathrm{ZnO}$ nanorods obtained by hydrolysis of zinc precursor in molar ratio of $1 / 1$ with presence of octylamine without additional solvent at room temperature.

The nanorods were further modified by $\mathrm{PEG}_{2 \mathrm{k}}-b-\mathrm{PAA}_{1 \mathrm{k}}$ or $\mathrm{PEG}_{2 \mathrm{k}}-b-\mathrm{PVPA}_{1 \mathrm{k}}$ in a similar manner to that described for isotropic ZnO NPs in THF and then transferred to water. TEM images were then recorded at different aging times to follow the evolution of shape. Figure 8 and Table 2 give an overview of the obtained results. In THF, a decrease of length of the $\mathrm{ZnO}$ nanorods covered by $\mathrm{PEG}_{2 \mathrm{k}}-b-\mathrm{PAA}_{1 \mathrm{k}}$ is observed (Figures $8 \mathrm{~A}$ and $8 \mathrm{~B}$ ). This decrease is more significant when $\mathrm{PEG}_{2 \mathrm{k}}-b-\mathrm{PVPA}_{1 \mathrm{k}}$ is used as a stabilizing agent. Indeed, 2D-plots show a strong decrease of nanoparticle length over time (from $45 \pm 26 \mathrm{~nm}$ to $20 \pm 17 \mathrm{~nm}$ after 7 days).

In water, this phenomenon is less pronounced (Figure S20 and Table S1), confirming NMR results that show a less reactive surface than in the case of THF. This digestion is slow and could therefore be of great interest for biological applications, as it will guarantee the disappearance of residual NPs after use and thus minimize long-term toxicity issues. 

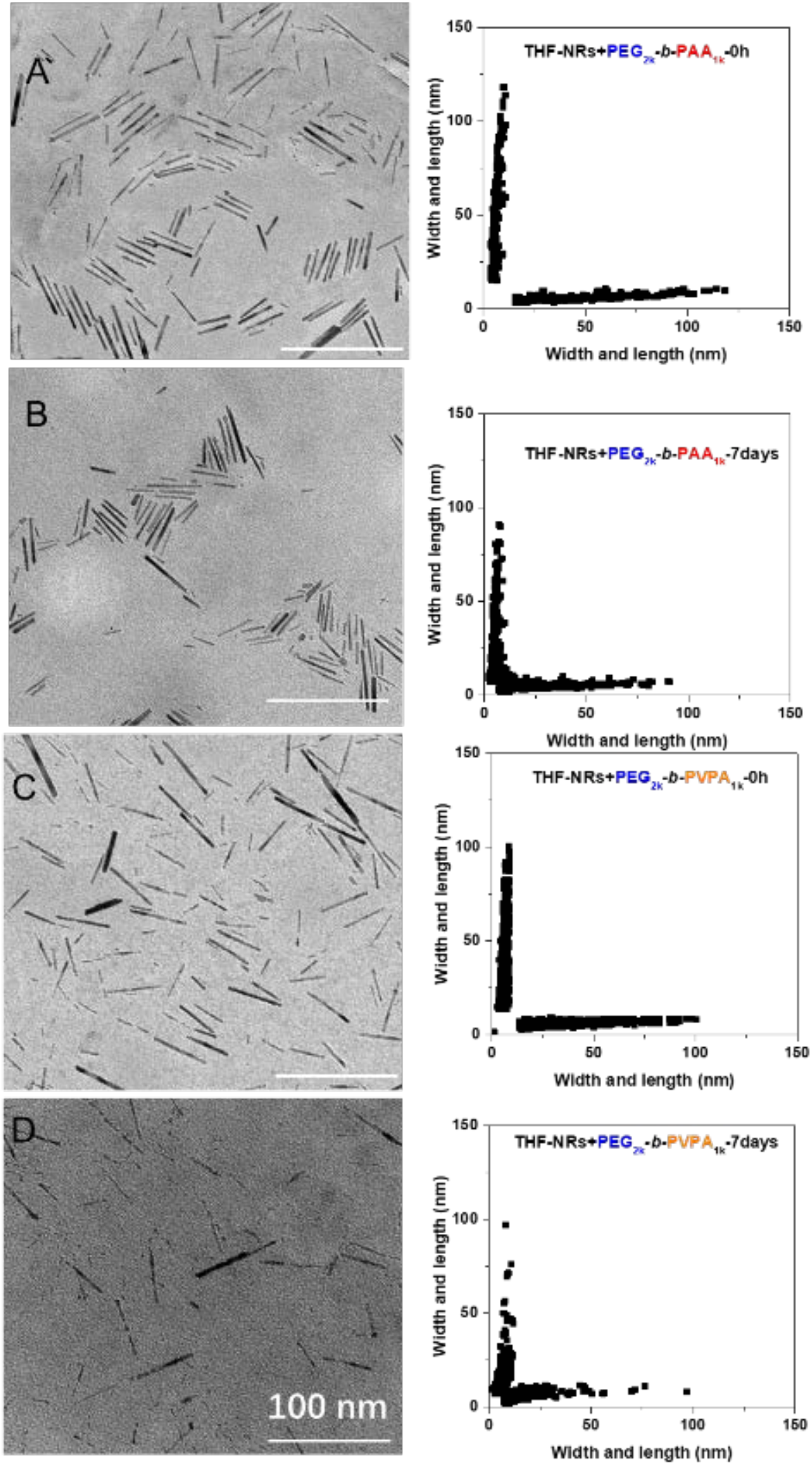

Figure 8. TEM images and corresponding 2D-plots of $Z n O$ nanorods coated by $P_{E G_{2 k}-b-P A A_{1 k}}(A$ and $B)$ or by $\mathrm{PEG}_{2 \mathrm{k}}-b$-PVPA ${ }_{1 \mathrm{k}}(\mathrm{C}$ and $\mathrm{D})$ immediately after modification by the polymer ( $\mathrm{A}$ and $\mathrm{C}$ ) or after 7-days aging in THF (B and $D)$. 
Table 2. Average dimensions of $\mathrm{ZnO}$ nanorods before and after coating in $T H F$ by $P E G_{2 k}-b-P A A_{1 k}$ or by $\mathrm{PEG}_{2 \mathrm{k}}-b-\mathrm{PVPA}_{1 \mathrm{k} .}$. immediately and after storage in THF solutions for 7 days.

\begin{tabular}{llll}
\hline & $\begin{array}{l}\text { No } \\
\text { Polymers } \\
(\mathrm{nm})\end{array}$ & $\begin{array}{l}+\mathrm{PEG}_{2 \mathrm{k}}-b- \\
\mathrm{PAA}_{1 \mathrm{k}}(\mathrm{nm})\end{array}$ & $\begin{array}{l}+\mathrm{PEG}_{2 \mathrm{k}}-b- \\
\mathrm{PVPA}_{1 k}(\mathrm{~nm})\end{array}$ \\
\hline Length (0h) & $36 \pm 14$ & $45 \pm 26$ & $34 \pm 20$ \\
Width (0h) & $6 \pm 1$ & $6 \pm 2$ & $6 \pm 1$ \\
Length (7days) & - & $20 \pm 17$ & $13 \pm 8$ \\
Width (7days) & - & $5 \pm 1$ & $5 \pm 2$ \\
\hline
\end{tabular}

\section{Experimental Section}

\section{Materials and methods.}

Materials. Dicyclohexyl zinc precursor, $\left[\mathrm{Zn}(\mathrm{cy})_{2}\right]$, was purchased from NANOMEPS (http://www.nanomeps.fr/). n-Octylamine (OA) was from Aldrich. Both compounds were used without further purification. Oxygen- and moisture-sensitive substances and reactions were handled either in an MBraun Inert Gas System or under an argon atmosphere in carefully dried glassware, by using standard Schlenk techniques. Vinyl phosphonic acid (VPA, 97\%) was purchased from Sigma Aldrich. Acrylic acid (AA, 99.5\%) and 2,2'-azobis(isobutyramidine) dihydrochloride (AIBA, 98\%) was supplied by Acros. Poly(ethylene glycol) monomethyl ether (PEG-OH) was supplied by Fluka. All reagents were used as received. 2-[(ethoxythiocarbonyl)thio]propionic acid (X1) was prepared according to a procedure described elsewhere. ${ }^{28}$ Spectra/Por ${ }^{\circledast}$ dialysis membrane (MWCO $1000 \mathrm{~g} \cdot \mathrm{mol}^{-1}$ ) was used for dialysis of (co)polymers. Water was purified through a filter and ion exchange resin using a Purite device (resistivity $18.2 \mathrm{M} \Omega \cdot \mathrm{cm}$ ).

Size exclusion chromatography (SEC) was performed on an Agilent 1100 HPLC system, an 18-angle Multi-Angle Light Scattering (MALS) DAWN-Heleos-II (Wyatt Technology, Santa Barbara, CA, US), an OptilaRex Refractometer (Wyatt Technology, Santa Barbara, CA, US) and a set of 2 columns (Shodex SB-806M and SB-802.5) thermostated at $30^{\circ} \mathrm{C}$. Water $\left(\mathrm{NaCl} 100 \mathrm{mmol} \cdot \mathrm{L}^{-1}, \mathrm{NaH}_{2} \mathrm{PO}_{4} 25 \mathrm{mmol} \cdot \mathrm{L}^{-1}\right.$, $\mathrm{Na}_{2} \mathrm{HPO}_{4} 25 \mathrm{mmol} \cdot \mathrm{L}^{-1}$, buffer solution at $\mathrm{pH}=7$ ) was used as eluent with a flow rate of $1.0 \mathrm{~mL} \cdot \mathrm{min}^{-1}$. The $\mathrm{dn} / \mathrm{dc}$ of PVPA $\left(0.144 \mathrm{~mL} \cdot \mathrm{g}^{-1}\right)$ was measured at $620 \mathrm{~nm}$ using a DNDC-2010 differential refractometer (PSS).

Dynamic Light Scattering (DLS). Measurements were carried out on a Malvern Instrument Nano-ZS equipped with a He-Ne laser $(\lambda=633 \mathrm{~nm})$. The correlation function was analyzed via the generalpurpose method (NNLS) to obtain the distribution of diffusion coefficients $(D)$ of the solutes. The apparent equivalent hydrodynamic diameter $\left(\left\langle D_{\mathrm{h}}\right\rangle\right)$ was then determined using the Stokes-Einstein equation. Mean diameter values were obtained from three different runs. Standard deviations were evaluated from diameter distribution.

Transmission electronic microscopy (TEM). Samples for TEM were prepared by slow evaporation of droplets of colloidal solution deposited on a carbon-coated 200 mesh copper TEM grid from the Ted Pella Company. The TEM experiments were performed at the microscopy service of University Paul 
Sabatier (TEMSCAN) by using a JEOL JEM1011 electron microscope operating at $100 \mathrm{kV}$ with a resolution point of $0.45 \mathrm{~nm}$. The nanoparticle size-distributions were determined by measuring a minimum of 200 particles of each sample. They were analyzed in terms of $2 \mathrm{D}$ plots statistics. ${ }^{26}$ The mean diameter and standard deviation are evaluated by fitting of the histogram with a Gaussian curve. $95 \%$ confidence interval were given (i.e. twice the standard deviation of the Gaussian distribution or approximately 0.849 the width of the peak at half-height).

Fluorescence Spectroscopy and UV-VIS Spectroscopy. Emission and excitation spectra were recorded either on a Horiba Jobin Yvon Fluoromax-4 spectrofluorometric equipped with a xenon lamp or a PTI spectrometer equipped with a xenon lamp. The solutions to be analysed were placed in Hellman precision cells made of Quartz SUPRASIL ${ }^{\circ}(10.00 \mathrm{~mm})$. Emission spectra were corrected taking into account the transmission of the monochromator and the response of the photomultiplier. Absorption spectra were recorded on a Hewlett Packard HP 8452A Diode Array Spectrophotometer with an optical path length of $1 \mathrm{~cm}$.

Nuclear Magnetic Resonance Spectroscopy (NMR). 1D and 2D ${ }^{1} \mathrm{H}$ liquid state NMR experiments were recorded on a Bruker Avance 500 spectrometer equipped with a $5 \mathrm{~mm}$ triple resonance inverse Zgradient probe. Samples were prepared in $\mathrm{D}_{2} \mathrm{O}$ or in THF- $d_{8} .{ }^{1} \mathrm{H}$ and ${ }^{13} \mathrm{C}$ signals were assigned on the basis of chemical shifts, spin-spin coupling constants, splitting patterns and signal intensities, and by using ${ }^{1} \mathrm{H}-{ }^{1} \mathrm{H}$ TOCSY, ${ }^{1} \mathrm{H}_{-}{ }^{13} \mathrm{C} \mathrm{HMQC}$ and ${ }^{1} \mathrm{H}-{ }^{13} \mathrm{C}$ HMBC experiments. The $2 \mathrm{D}$ NOESY measurements were done with a mixing time of $100 \mathrm{~ms}$. Diffusion measurements were made using the stimulated echo pulse sequence with bipolar gradient pulses. The diffusion dimension was processed with the Laplace inversion routine CONTIN (Topspin software). Parameters of the diffusion-filtered ${ }^{1} \mathrm{H}$ NMR experiment were chosen in order to suppress the signal of fast diffusing species (solvent and free or weakly interacting OA molecules).

Solid state NMR experiments were recorded on a Bruker Avancelll 400 spectrometer. Samples were packed into $4 \mathrm{~mm}$ zirconia rotors inside a glove box. The rotors were spun at 8 or $10 \mathrm{kHz}$ at $293 \mathrm{~K}$. ${ }^{13} \mathrm{C}$ MAS with direct polarization were acquired with a small flip angle of $30^{\circ}$ and a recycle delay of $10 \mathrm{~s}$. ${ }^{13} \mathrm{C}$ and ${ }^{31} \mathrm{P}$ with Cross Polarization (CP) were recorded with a recycle delay of $1.5 \mathrm{~s}$ and a contact time of $2 \mathrm{~ms} .{ }^{1} \mathrm{H}$ and ${ }^{13} \mathrm{C}$ chemical shifts are relative to TMS and ${ }^{31} \mathrm{P}$ chemical shifts were referenced to an external $85 \% \mathrm{H}_{3} \mathrm{PO}_{4}$ sample.

\section{B. Synthesis.}

Synthesis of isotropic ZnO NPs. In a Schlenk tube protected with aluminium foil, dicyclohexyl zinc (57.9 $\mathrm{mg}, 1 \mathrm{eq})$ and $\mathrm{OA}(32.3 \mathrm{mg}, 1 \mathrm{eq})$ were mixed together in THF $(5 \mathrm{~mL})$ under an argon atmosphere inside a glovebox. The reaction mixture was then stirred the room temperature. Addition of water (in the liquid form, $9 \mu \mathrm{L}$, 2 eq.) was then performed within $2 \mathrm{ml}$ THF. The water mixture was injected into the same Schlenk tube. The 7-mL mixture was maintained under these conditions for 12 hours.

Synthesis of anisotropic ZnO NPs. In a $7 \mathrm{~mL}$ clean glass bottle protected with aluminium foil, dicyclohexyl zinc $(57.9 \mathrm{mg}, 1 \mathrm{eq})$ and $\mathrm{OA}(32.3 \mathrm{mg}, 1 \mathrm{eq})$ were mixed together under an argon atmosphere inside a glovebox. The reaction mixture was shaken for $30 \mathrm{~min}$ and then exposed to air at room temperature. The mixture was maintained under these conditions for 12 hours.

Synthesis of PEG-X1 macro-RAFT agents. i) Synthesis of PEG-Br. PEG-X1 was obtained using commercially available $\mathrm{CH}_{3}\left(\mathrm{OCH}_{2} \mathrm{CH}_{2}\right)_{45} \mathrm{OH}\left(\mathrm{PEG}-\mathrm{OH}, \mathrm{M}=2012 \mathrm{~g} \cdot \mathrm{mol}^{-1}\right)$. PEG-OH (20 g, $0.01 \mathrm{~mol}^{2}$ ), Et ${ }_{3} \mathrm{~N}$ (1.77 g; $0.03 \mathrm{~mol}), \mathrm{CH}_{2} \mathrm{Cl}_{2}(50 \mathrm{~mL})$ were placed in the flask and the mixture was degassed by bubbling argon for $10 \mathrm{~min}$. Then, 2-bromopropionyl bromide was added dropwise at $0^{\circ} \mathrm{C}$. The reaction mixture temperature was raised to room temperature and stirred for $20 \mathrm{~h}$. The white precipitate $\left(\mathrm{Et}_{3} \mathrm{NHBr}\right)$ was 
filtered and the solvent was evaporated under reduced pressure. $200 \mathrm{~mL}$ of $\mathrm{CH}_{2} \mathrm{Cl}_{2}$ was added and the mixture was washed with a saturated ammonium chloride solution $(2 \times 30 \mathrm{~mL})$, next with a sodium carbonate saturated solution $(4 \times 40 \mathrm{~mL})$ and finally with pure water $(5 \times 50 \mathrm{~mL})$. The organic phase was dried over $\mathrm{Na}_{2} \mathrm{SO}_{4}$. After filtration and evaporation of the solvent, $17.2 \mathrm{~g}(80 \%)$ of a white powder was obtained.

Synthesis of PEG-X1. PEG-Br (16.7 g, $7.64 \mathrm{mmol})$ was placed in a flask under of argon atmosphere. The solvent (anhydrous $\mathrm{CH}_{2} \mathrm{Cl}_{2}, 100 \mathrm{~mL}$ ) and ethyl potassium xanthate ( $3.75 \mathrm{~g}, 23.4 \mathrm{mmol}$ ) were added. The reaction mixture was stirred at room temperature for $17 \mathrm{~h}$. Then, half of the solvent was evaporated under reduced pressure, the solution was filtered to remove precipitated salt ( $\mathrm{KBr}$ ). The resulting solution was viscous and yellow. The product was precipitated from pentane $(3 \times 200 \mathrm{~mL})$ and dried under reduced pressure. $12.93 \mathrm{~g}$ of beige powder was obtained (77\%). $\mathrm{PEG}_{2 \mathrm{~K}}-\mathrm{X} 1{ }^{1} \mathrm{H}$ NMR $\delta(\mathrm{ppm})\left(\mathrm{D}_{2} \mathrm{O}\right.$, $300.13 \mathrm{MHz}$ ): $1.33\left(\mathrm{t}, 3 \mathrm{H},-\mathrm{CH}_{2}-\mathrm{CH}_{3}\right), 1.49\left(\mathrm{~d}, 3 \mathrm{H}, \mathrm{CH}-\mathrm{CH}_{3}\right), 3.32\left(\mathrm{~s}, 3 \mathrm{H},-\mathrm{O}-\mathrm{CH}_{3}\right), 3.50-3.70\left(\mathrm{~m},-\mathrm{O}-\mathrm{CH}_{2}-\right.$ $\left.\mathrm{CH}_{2}-\mathrm{O}-\right)$, 4.32-4.42 (m, $\left.1 \mathrm{H}, \mathrm{CH}-\mathrm{CH} 3\right), 4.55-4.65\left(\mathrm{~m}, 2 \mathrm{H},-\mathrm{CH}_{2}-\mathrm{CH}_{3}\right)$.

Synthesis of PEG Pk- $\boldsymbol{b}$-PVPA $1 \mathrm{k}$ diblock copolymer. PEG-X1 $(0.75 \mathrm{~g}, 0.34 \mathrm{mmol}), \mathrm{VPA}(0.76 \mathrm{~g}, 7.0 \mathrm{mmol})$ and water $(1 \mathrm{~mL})$ were placed in a Schlenk flask equipped with a magnetic stirrer and were degassed by bubbling argon for $30 \mathrm{~min}$. Then, AIBA ( $14 \mathrm{mg}, 0.05 \mathrm{mmol}$ ) was added and the solution was heated at $65^{\circ} \mathrm{C}$ for $8 \mathrm{~h}$, reaching $50 \%$ conversion. The resulting polymer was purified by dialysis ( $\mathrm{MWCO}=1000$ $\left.\mathrm{g} \cdot \mathrm{mol}^{-1}\right)$ and freeze dried. $\mathrm{PEG}_{2 \mathrm{~K}}-b-\mathrm{PVPA}_{1 \mathrm{~K}}{ }^{1} \mathrm{H}$ NMR $\delta(\mathrm{ppm})\left(\mathrm{D}_{2} \mathrm{O}, 300.13 \mathrm{MHz}\right): 1.33-1.49\left(\mathrm{~m}, 6 \mathrm{H},-\mathrm{CH}_{2}-\right.$ $\left.\mathrm{CH}_{3}, \mathrm{CH}-\mathrm{CH}_{3}\right), 1.50-3.00$ (m, $\left.-\mathrm{CH}_{2}-\mathrm{CH}-\right), 3.32\left(\mathrm{~s}, 3 \mathrm{H},-\mathrm{O}-\mathrm{CH}_{3}\right), 3.50-3.80\left(\mathrm{~m},-\mathrm{O}-\mathrm{CH}_{2}-\mathrm{CH}_{2}-\mathrm{O}-\right), 4.20$ (-CH-S). $\mathrm{PEG}_{2 \mathrm{~K}}-\mathrm{b}-\mathrm{PVPA}_{1 \mathrm{~K}}{ }^{31} \mathrm{P}$ NMR $\delta(\mathrm{ppm})\left(\mathrm{D}_{2} \mathrm{O}, 121.50 \mathrm{MHz}\right.$ ): 15.5 (residual VPA, < 5 mol\%), 19.0 (terminal VPA unit -P-CH(-S-)- $\mathrm{CH}_{2}-$ ), 29-33 (main chain VPA unit - $\mathrm{P}-\mathrm{CH}-\mathrm{CH}_{2}-$ ).

Synthesis of PEG $_{2 \mathrm{k}}-\boldsymbol{b}$-PAA $1 \mathrm{k}$ diblock copolymer. PEG-X1 (0.5 g, $\left.0.25 \mathrm{mmol}\right)$, acrylic acid $(0.125 \mathrm{~g}, 1.74$ $\mathrm{mmol})$ and water $(1 \mathrm{~mL})$ were placed in a Schlenk flask equipped with a magnetic stirrer and were degassed by bubbling argon for $30 \mathrm{~min}$. Then, AIBA $(4.8 \mathrm{mg}, 0.017 \mathrm{mmol})$ was added and the solution was heated at $65^{\circ} \mathrm{C}$ for $8 \mathrm{~h}$. The products were purified by dialysis and freeze dried. ${ }^{1} \mathrm{H}$ NMR $\delta(\mathrm{ppm})$ $\left(\mathrm{D}_{2} \mathrm{O}, 300.13 \mathrm{MHz}\right): 1.10-1.35\left(\mathrm{~m}, 6 \mathrm{H},-\mathrm{CH}_{2}-\mathrm{CH}_{3}, \mathrm{CH}-\mathrm{CH}_{3}\right), 1.40-2.70\left(\mathrm{~m},-\mathrm{CH}_{2}-\mathrm{CH}-\right), 3.32\left(\mathrm{~s}, 3 \mathrm{H},-\mathrm{O}-\mathrm{CH}_{3}\right)$, 3.50-3.80 (m, -O-CH-CH $-\mathrm{O}-\mathrm{O}), 4.20$ (-CH-S-).

Synthesis of PVPA homopolymer. PVPA homopolymer was prepared according to the modified procedure of Blidi et al. ${ }^{28}$ Xanthate X1 (156 mg, $\left.0.8 \mathrm{mmol}\right)$, VPA (1.033 g, $\left.9.26 \mathrm{mmol}\right), \mathrm{NaOH}(0.185 \mathrm{~g}$, $4.63 \mathrm{mmol})$, AIBA (18 mg, $0.068 \mathrm{mmol}$ ) and distilled water $(0.5 \mathrm{~mL}$ ) were placed in a Schlenk flask. The solution was then degassed by bubbling argon for $15 \mathrm{~min}$. The reaction mixture was heated at $65^{\circ} \mathrm{C}$ for $8 \mathrm{~h}$ in an oil bath. VPA conversion determined by ${ }^{31} \mathrm{P}$ NMR was $85 \%$. The product was purified by precipitation from methanol.

\section{Modification of ZnO NPs by polymer and transfer in water.}

$250 \mu \mathrm{L}$ of ZnO NPs THF solution were mixed with THF solutions of polymers (with a molar ratio 1:1 between OA and acidic function AA or VPA). The volume was adjusted to $1 \mathrm{~mL}$ and sonicated for $5 \mathrm{~min}$. Then $50 \mu \mathrm{L}$ of this mixture was diluted 40 -times by THF and sonicated for $2 \mathrm{~min}$. For transferring NPs into water, $50 \mu \mathrm{L}$ of the pristine solution in THF was taken and THF was removed by vacuum pump. 2 $\mathrm{mL}$ of water was added to the residue and sonicated for $2 \mathrm{~min}$.

\section{Conclusions}

Low molar mass poly(ethylene glycol)-poly(vinylphosphonic acid) and poly (ethylene glycol)poly(acrylic acid) block copolymers (PEG-b-PVPA and PEG-b-PAA) were synthesized by RAFT/MADIX 
polymerization and characterized. These two types of polymers were then used to modify the surface of preformed ZnO NPs covered by amine ligands.

After modification, stable colloidal solutions were obtained in THF. Interestingly, whereas luminescence remains constant for pristine $\mathrm{ZnO} N \mathrm{Ns}$, an increase of luminescence is observed for $\mathrm{ZnO}$ NPs modified by the two types of polymers. These modifications may be ascribed to changes in the $\mathrm{ZnO}$ surface induced by polymer adsorption and displacement of OA. NMR experiments showed the adsorption of $\mathrm{PEG}_{2 \mathrm{k}}-b-\mathrm{PAA}_{1 \mathrm{k}}$ and $\mathrm{PEG}_{2 \mathrm{k}}-b-\mathrm{PVPA}_{1 \mathrm{k}}$ on the surface of $\mathrm{ZnO} N \mathrm{NP}$ and additional interaction with OA through acid-base reaction. A higher affinity with OA is observed in the case of PVPA-based polymers but this does not significantly impact the colloidal and luminescent properties in THF compared to PAA-based polymers.

In water, whereas pristine ZnO NPs covered by OA quickly precipitate, stable colloidal solutions were obtained for polymer-modified ZnO NPs as a result of their diblock structure. In both cases, the release of $\mathrm{OA}$ from the surface is significantly slower than for $\mathrm{ZnO} / \mathrm{OA}$ and the precipitation of the nanoparticles is consequently delayed. Moreover the interactions between $\mathrm{PEG}_{2 \mathrm{k}}-b-\mathrm{PAA}_{1 \mathrm{k}}$ or $\mathrm{PEG}_{2 \mathrm{k}}-b-$ $\mathrm{PVPA}_{1 \mathrm{k}}$ and $\mathrm{ZnO}$ surface and OA prevent fast hydroxylation of the surface. Nevertheless for both copolymers, a decrease of the absorbance and of the luminescence are observed over a long period of time (typically several days). As demonstrated on $\mathrm{ZnO}$ nanorods, a slow digestion mechanism is suggested. This phenomenon occured more rapidly in the case of ZnO NPs covered with PVPA-based copolymer than for the PAA-based copolymer. This mechanism could be of great interest in biological applications to avoid the accumulation of NPs in vivo. This will be the focus of further studies.

\section{Acknowledgements}

The authors wish to thank the China Scholarship Council (CSC) and the CNRS for funding.

\section{References}

1 S. Saliba, C. Valverde Serrano, J. Keilitz, M. L. Kahn, C. Mingotaud, R. Haag and J. D. Marty, Chem. Mater., 2010, 22, 6301.

2 W. C. Chan and S. Nie, Science 1998, 281, 2016; M. Bruchez, M. Moronne, P. Gin, S. Weiss and A. P. Alivisato, Science, 1998, 281, 2013.

3 Y. Wu, C. Lim, S. Fu, A. Tok, H. Lau, F. Boey and X. Zeng, Nanotechnology, 2007, 18, 215604.

4 M. Beija, N. Lauth-de Viguerie, R. Salvayre and J. D. Marty, Trends Biotechnol., 2012, 30 (9), 485.

5 L. Spanhel and M. A. Anderson, J. Am. Chem. Soc., 1991, 113, 2826.

6 J. Turkevich, P. C. Stevenson and J. Hillier, Discuss. Faraday Soc., 1951, 11, 55.

7 P. Zrazhevskiy, M. Sena and X. Gao, Chem. Soc. Rev., 2010, 39, 4326.

8 S. A. Kulinich, J. S. Qiu, W. J. Qin, R. Li, J. Sun and J. Liu, J. Am. Chem. Soc., 2007, 129, 16029.

9 H. M. Xiong, Y. Xu, Q. G. Ren and Y. Y. Xia, J. Am. Chem. Soc., 2008, 130, 7522.

10 N. R. Jana, H. H. Yu, E. M. Ali, Y. Zheng and J. Y. Ying, Chem. Commun. 2007, 140; R. O. Moussodia, L. Balan and R. Schneider, New J. Chem., 2008, 32, 1388.

11 X. Tang, E. S. G. Choo, L. Li, J. Ding and J. Xue, Chem. Mater., 2010, 22, 3383.

12 J. Rubio-Garcia, Y. Coppel, P. Lecante, C. Mingotaud, B. Chaudret, F. Gauffre and M. L. Kahn, Chem. Commun., 2011, 47, 988.

13 M. Beija, J. D. Marty and M. Destarac, Progr. Polym. Sci., 2011, 36, 845.

14 W. Brullot, N. K. Reddy, J. Wouters, V. K. Valev, B. Goderis, J. Vermont and T. J. Verbiest, J. Magn. Magn. Mater., 2012, 324, 1919.

15 R. Quiñones, K. Rodriguez and R. Iuliucci, Thin Solid Films, 2014, 565. 155.

16 a) K. Markiewicz, L. Seiler, I. Misztalewska, K. Winkler, S. Harrisson, A. Wilczewska, M. Destarac and J. D. Marty, Polym. Chem. 2016, 7, 6391. b) T. Sahoo, H. Pizem, T. Fried, D. Golodnitsky, L. Burstein, C.M. 
Subenik and G. Markovich, Langmuir, 2001, 17, 7907. c) C. Boyer, V. Bulmus, P. Priyanto, W. Yang Teoh, R. Amal and T.P. Davis, J. Mater. Chem., 2009, 19, 111. d) L. Qi, A. Sehgal, J.-C. Castaing, J.-P. Chapel, J. Fresnais, J.-F. Berret and F. Cousin, ACS Nano, 2008, 2, 879. e) C. Ghorbil, G. Popa, A. Parat, C. Billotey, J. Taleb, P. Bonazza, S. Begin-Colin and D. Felder-Flesch, Chem. Commun., 2013, 49, 9158.

17 G. Pound, F. Aguesse, J. B. McLeary, R. F. Lange and B. Klumperman, Macromolecules 2007, 40, 8861.

18 a) G. Layrac, C. Gerardin, D. Tichit, S. Harrisson and M. Destarac, Polymer, 2015, 72, 292. b) L. Seiler, J. Loiseau, F. Leising, P. Boustingorry, S. Harrisson, M. Destarac, Polym. Chem. 2017, 8, 3825.

19 M. Monge, M. L. Kahn, A. Maisonnat and B. Chaudret, Ang. Chem. Int. Ed., 2003, 42, 5321.

20 R. O. Moussodia, L. Balan, C. Merlin, C. Mustin and R. Schneider, J. Mater. Chem., 2010, $20,1147$.

21 a) M. Vaseem, A. Umar and Y. B. Hahn, in Metal Oxide Nanostructures and Their Applications, Vol 5. (Eds A. Umar and Y.-B. Hahn), American Scientific Publishers, 2010, chapter 4, pp 1-36 b); M. A. Vergés, A. Mifsud and C. Serna, J. Am. Chem. Soc., Faraday Transactions 1990, 86, 959.

22 Z. Zhao, Z. Zheng, C. Roux, C. Delmas, J. D. Marty, M. L. Kahn and C. Mingotaud, Chem. Eur. J., 2016, 22, 12424.

23 A. Van Dijken, E. Meulenkamp, D. Vanmaekelbergh, and A. Meijerink, J. Lumin., 2000, 90, 123.

24 Y. Coppel, G. Spataro, B. Chaudret, A. Maisonnat and M. L. Kahn, Chem. Eur. J., 2012, 18, 5384.

25 B. Fritzinger, I. Moreels, P. Lommens, R. Koole, Z. Hens and J. C. Martins, J. Am. Chem. Soc., 2009, 131, 3024.

26 Y. Coppel, G. Spataro, V. Collière, B. Chaudret, C. Mingotaud, A. Maisonnat and M. L. Kahn, Eur. J. Inorg. Chem., 2012, 2691.

27 C. N. Valdez, A. M. Schimpf, D. R. Gamelin and J. M. Mayer, ACS Nano, 2014, 8, 9463.

I. Blidi, R. Geagea, O. Coutelier, M. Mazières, F. Violleau and M. Destarac, Polym. Chem., 2012, 3, 609. 